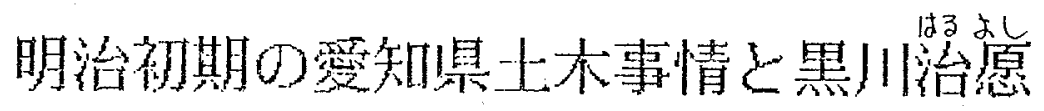

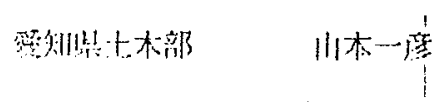

\begin{abstract}
榴: 装

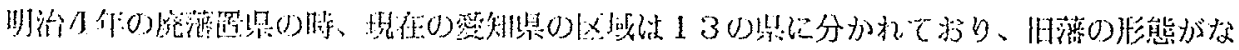

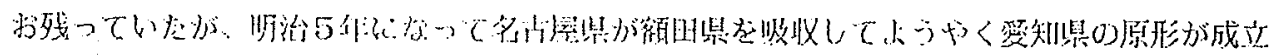

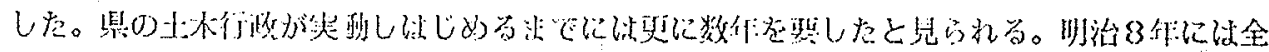

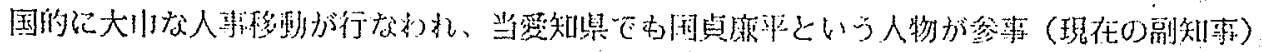

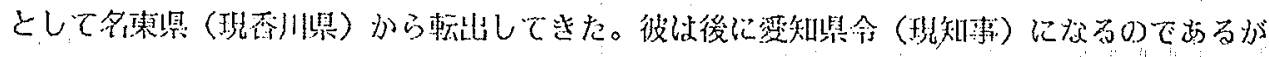

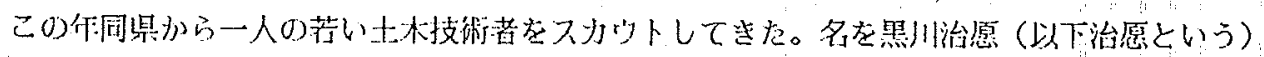

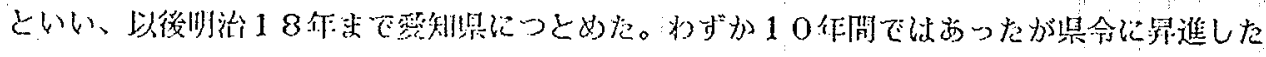

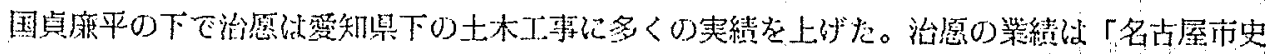

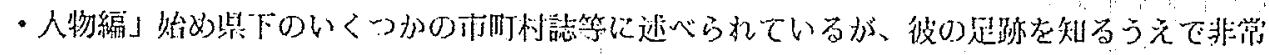

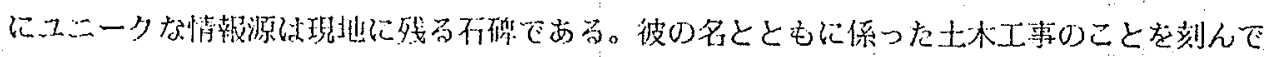

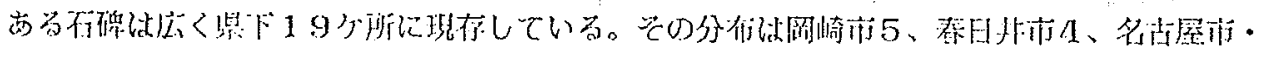

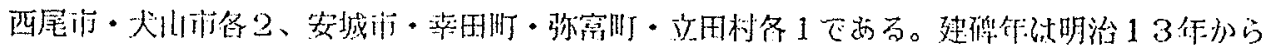

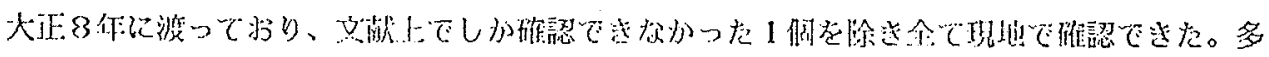

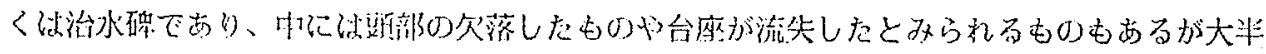

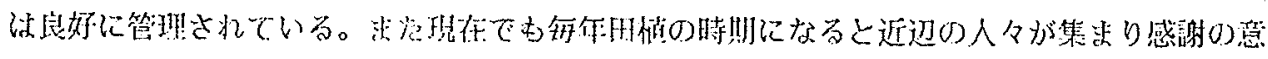

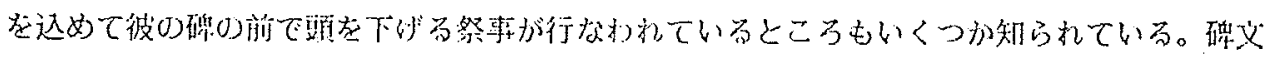

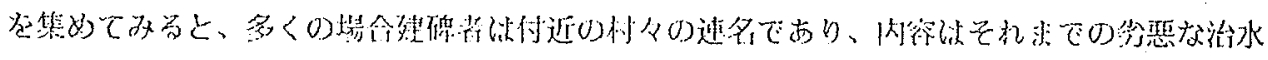

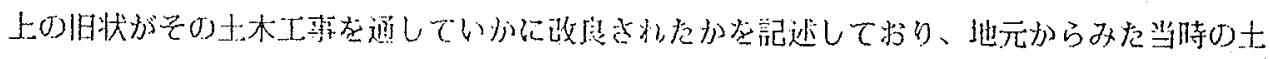

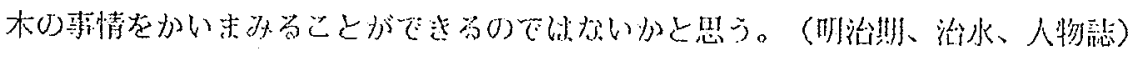

\section{1. 㥿川治愿小伝}

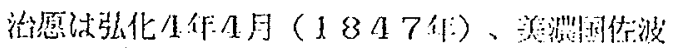

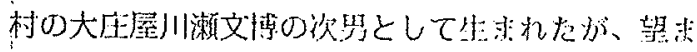

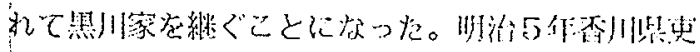
となったが、明治8年糸知累以轻出した。明治17

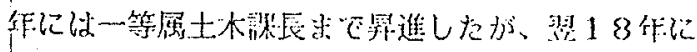

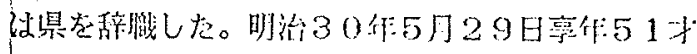

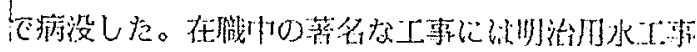

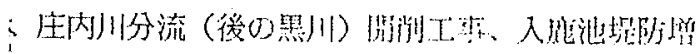

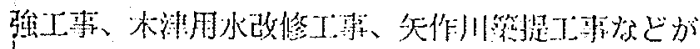

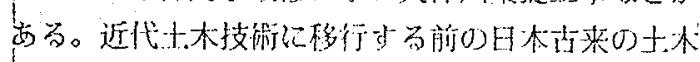

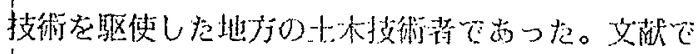

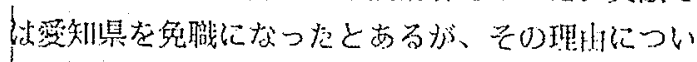

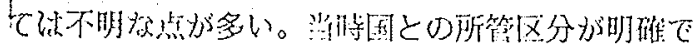

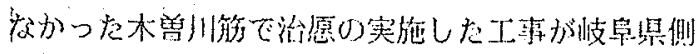

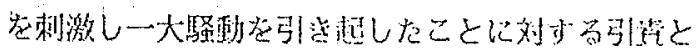

妌号起学。

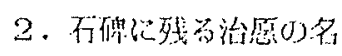

\section{(1) 叮治沙水缩}

安城标

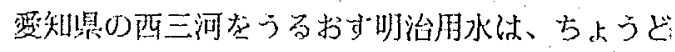

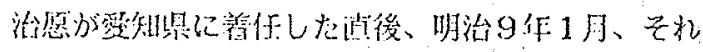

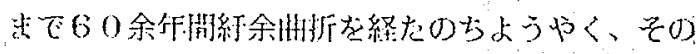

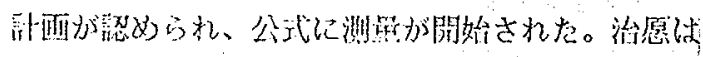

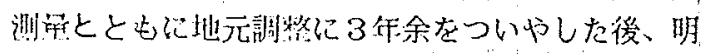

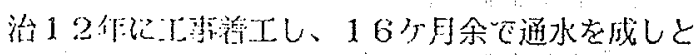

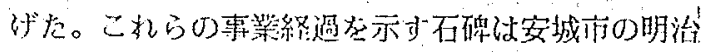

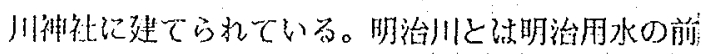

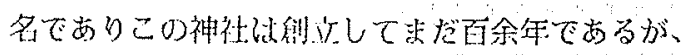

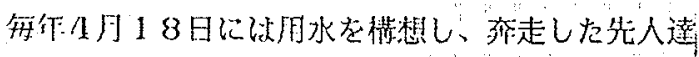

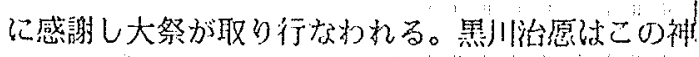

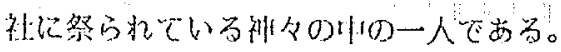




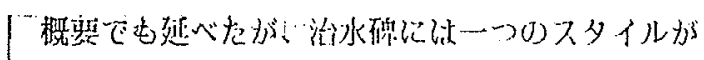

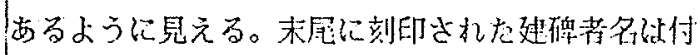

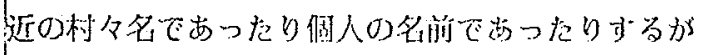

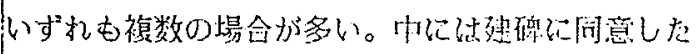

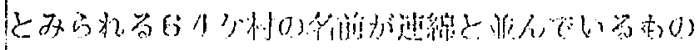

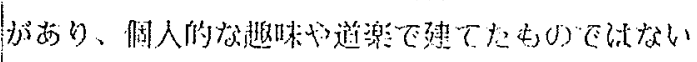

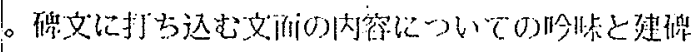

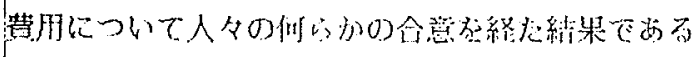

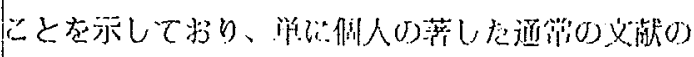

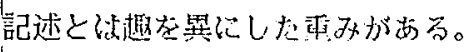

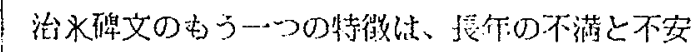

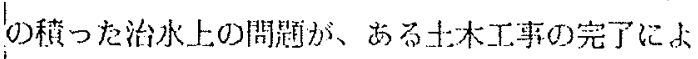

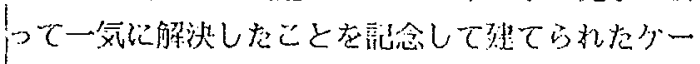

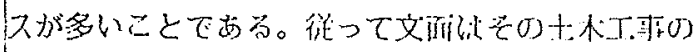

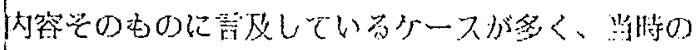

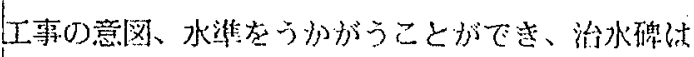

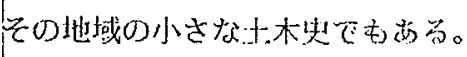

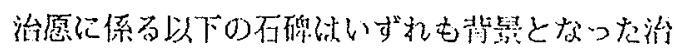

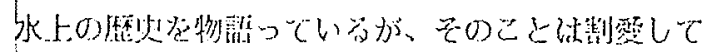

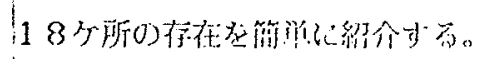

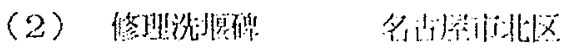

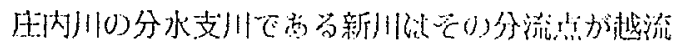

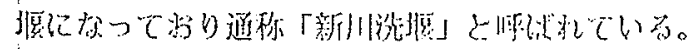

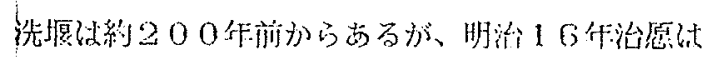

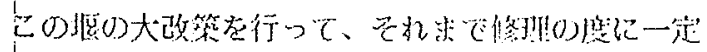

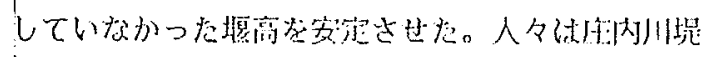

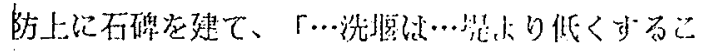

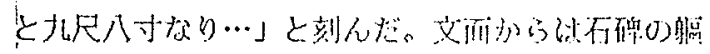

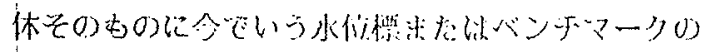

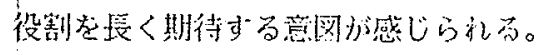

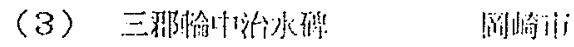

矢作川支流乙川的吸治 15 年1 0 月1 日

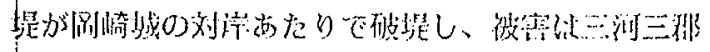

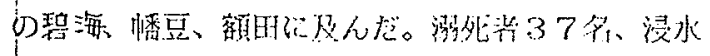

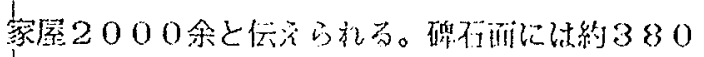

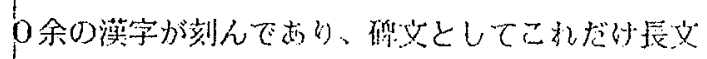

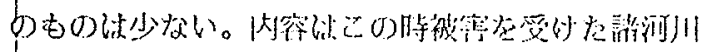

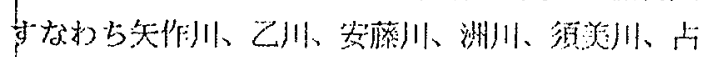

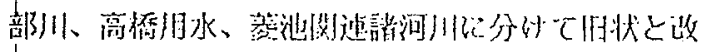

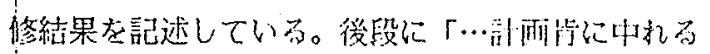

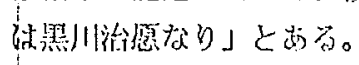
(4) 增穿鵜王川解
立因村

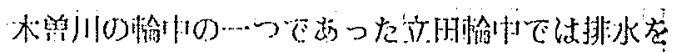
めぐって錸打の上流部と下流部で流向の紛争を起

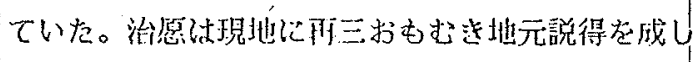

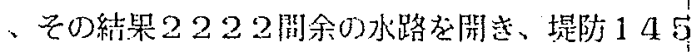

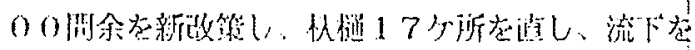

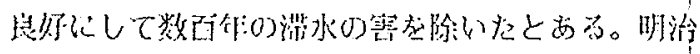

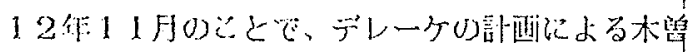

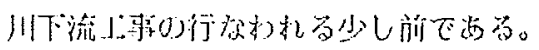

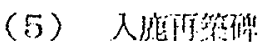
犬曰!戗

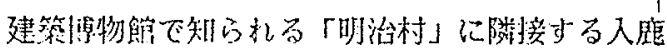

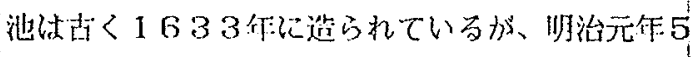

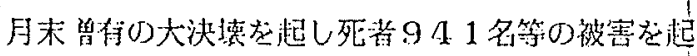

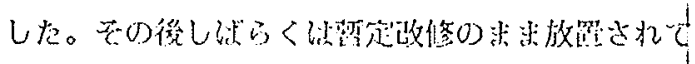
いたが哟治 12 个になって治愿の計画によって大瞡

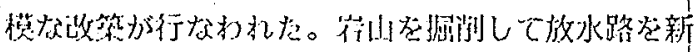
設し、その排洌残十芝うまく使い堤防の腹付・強化

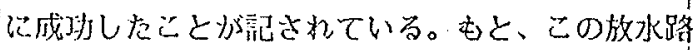
付近に古った碑如今は昆跡上に移さ机ている。

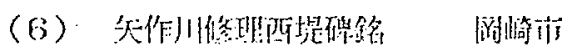

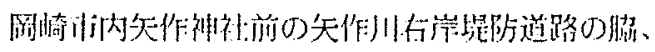

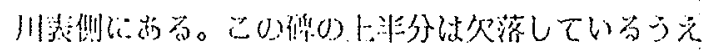

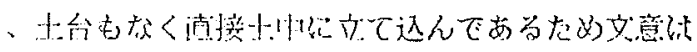

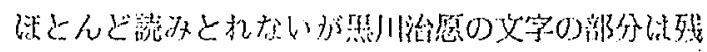

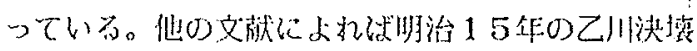

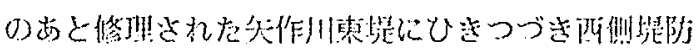

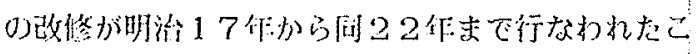

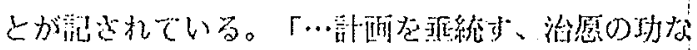
り…」と颠号。

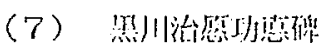

弥富沺

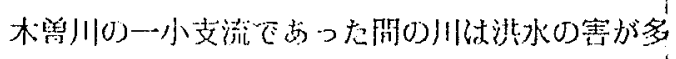

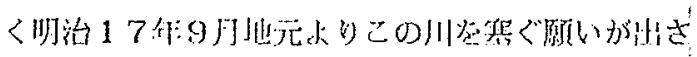

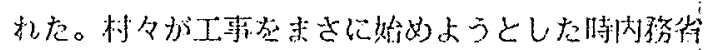

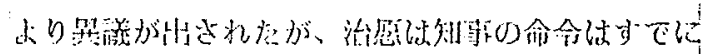

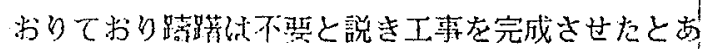

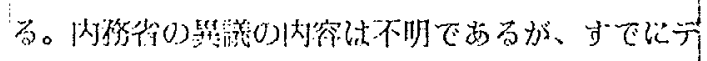

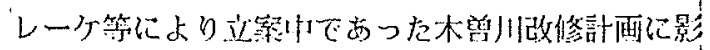

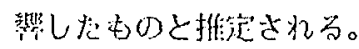

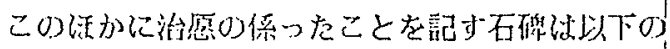
とおりで岁る。

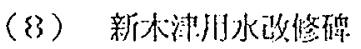
洯日扑市
（9）上條新田踏拓碑 


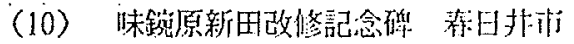

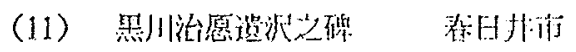

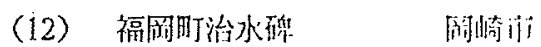

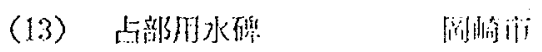

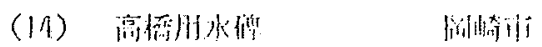

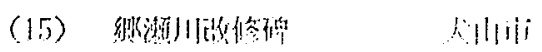

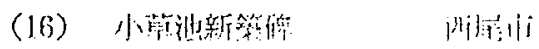

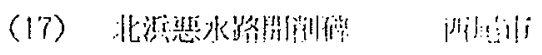

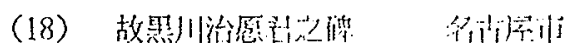

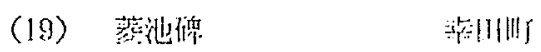

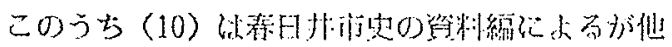
视视し。
3. 然莎文献

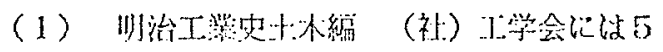
分所で汾㹸のことが通べられている。18 $1 \mathrm{p}, 7 / 4 \mathrm{p}, 315 \mathrm{p}, 822 \mathrm{p}, 8$

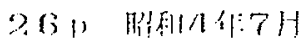

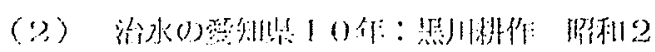

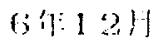

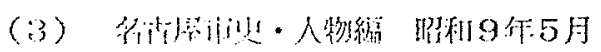

